\title{
Metastatic Medulloblastoma
}

\author{
DWIGHT PARKINSON, R. T. ROSS and CHRISTOPHER B. SHIELDS
}

SUMMARY: The incidence of metastatic medulloblastoma is probably greater than the thirteen documented patients. Case reports of metastatic medulloblastoma must be carefully analysed. We have added two cases which conform to Weiss' criteria for metastatic disease. The direction and factors influencing spread have been discussed.

RESUME: L'incidence de médulloblastomes métastatiques est probablement plus grande que les 13 cas rapportés. Les publications incluant des cas de médulloblastome métastatique doivent en effet être analysés soigneusement. Nous incluons deux cas se conformant aux critères de Weiss pour la maladie métastatique. Les facteurs influençant l'étendue et la direction de propagation ont été discutés.

From the Department of Neurosurgery and Department of Neurology, Faculty of Medicine, University of Manitoba, Winnipeg, Canada.

Reprint address: Dr. D. Parkinson, 1613 - 233 Kennedy St., Winnipeg R3C 3J5, Canada.
Tumors of the central nervous system metastasizing to other organs are rare. (Paterson, 1961; Nelson, 1936; Russell, 1959.)

Nelson (1936) was the first to report a case of metastatic medulloblastoma. Oberman (1963) stated that only five of sixteen reported cases were sufficiently well documented to be reliable and added one of his own. Since 1963 five more cases (Corrin, 1967; Drachman, 1963; Duckett, 1963; MacKeevor, 1966; Schenk, 1966) have fulfilled the criteria outlined by Weiss (1955). These criteria are:

1) the presence of a single histologically characteristic tumor of the central nervous system.

2) a clinical history which demonstrates that the tumor accounted for the initial symptoms.

3) a complete necropsy to exclude the presence of another primary tumor.

4) Identical morphology of the primary lesion and the metastasis.

In ten years, two patients meeting these criteria have been followed in this center.

\section{CASE REPORTS}

Patient 1: In 1961, a 9 month girl presented with the clinical and radiographic signs of a cerebellar tumor which was treated by surgical removal and radiation to the entire cerebrospinal axis. Microscopic examination revealed sheets of cells with hyperchromic ovalshaped nuclei, numerous mitotic figures, scanty cytoplasm, little vascularity and no pseudorosettes. In other areas there were islands of paler homogeneous cells, well demarcated from the surrounding areas. This tumor was classified as a desmoplastic medulloblastoma (Russell, 1959; Rubenstein, 1964). Sixteen months post-operatively a soft tissue swelling of the left anterior thorax appeared. An osteosclerotic lesion of the left 8th rib, and left pleural effusion were shown by $\mathrm{x}$-ray. Thoracentesis recovered $300 \mathrm{cc}$ 's of bloody fluid, containing clumps of tumor cells. Chest wall biopsy revealed tumor similar to that from the cerebellum. The patient died from recurrent pleural effusions seventeen months post-craniotomy. At autopsy there was no gross or microscopic evidence of recurrent tumor in the cerebellum. Numerous soft, dark purple nodules measuring up to $2 \mathrm{cms}$. in diameter studded the left pleura. The left 7 th, 8 th and 9 th ribs and adjacent soft tissues were replaced by tumor having the same microscopic morphology as the cerebellar tumor. The spinal cord was not examined. The adrenals and paravertebral sympathetic chain were normal as was the remainder of the autopsy.

Patient 2: In 1968, a 22-year-old male taxidermist presented with signs and symptoms of a posterior fossa tumor which was removed at surgery. This proved to be a medulloblastoma with diffuse sheets of tumor cells having oval and carrot-shaped nuclei, scanty cytoplasm, a few mitotic figures and no pseudorosettes. Radiotherapy to the head $(4,550$ rads in 21 treatments) and spinal canal $(4,425 \mathrm{rads}$ in 26 treatments) followed surgery. Twenty-one months post-operatively, he developed pain in the right hip. Sclerotic lesions in the left and right iliac bones and right ischium were demonstrated radiologically. They were also present in both scapulae, right 6 th rib, and left 6 th and 7 th ribs. Biopsy of the pelvic lesion revealed a tumor having similar morphology to the cerebellar tumor. Local short term radiotherapy, vincristine sulphate (5 grams) and cyclophosphamide (21/2 grams) gave no symptomatic relief and he died two years after craniotomy. At autopsy there was no tumor in the cerebellum. Numerous tumor nodules were found over the dorsal aspect of the entire spinal cord. There was also a tumor nodule adherent to the ependymal surface of the left lateral ventricle. A 1.5 $\mathrm{cm}$. diameter, finely nodular tumor encased the left optic nerve. A section of a 
lumbar vertebral body showed sheets of small tumor cells with similar morphology to the cerebellar tumor. Many areas considered to be secondary deposits radiologically showed only radiation fibrosis at autopsy. The paravertebral sympathetic chain and adrenals were normal.

\section{DISCUSSION}

Black (1963) described three patients whom he considered to meet Weiss' criteria (1955). However, no mention is made of the adrenals or sympathetic chain in his first two patients and his third patient was still alive at the time of reporting. This third patient subsequently came to autopsy and a paravertebral sympathetic neuroblastoma was found with metastases to cerebellum, bone, lung, liver, pancreas and spleen. Mikaye (1964) also described a cerebellar medulloblastoma with distant metastases, however, the paravertebral sympathetic chain revealed a neuroblastoma.

No mention is made of the adrenal glands or sympathetic chains in many patients; for example, Rubenstein and Northfield's (1964) patients 1 and 2, and Gyepes and D'Angio's (1966) patients 1,2 and 3. Lassman (1969) described two patients with metastatic cerebellar medulloblastoma during life, and therefore the possibility of a primary adrenal or sympathetic neuroblastoma cannot be excluded.

Both patients described here presented with clinical and radiologic evidence compatible with a posterior fossa mass. In both, the surgical specimens were diagnostic of medulloblastoma. Even this is insufficient to incriminate the cerebellar medulloblastoma as primary, as either a paravertebral sympathetic neuroblastoma or adrenal neuroblastoma may be histologically indistinguishable from medulloblastoma. However, adrenal glands and sympathetic chains were normal at autopsy.

Mechanical barrier of vessels to tumor cells at the primary site and inadequate local environment for tumor cell survival in potential secondary sites have been suggested (Rubenstein, 1964) as reasons for the infrequent occurrence of extraneural spread of medulloblastomas.
Zimmerman (1957) believes that the vessel wall barrier is the more important factor in preventing tumor metastasis. In support of this contention, he induced gliomas in mice and subsequently injected an allograft of glioma cell suspension intravenously and found metastases in liver, kidneys, spleen and lungs.

The absence of metastasis to lung is worthy of note (Drachman, 1963; Russell, 1959). Only one patient with a medulloblastoma metastasizing to lung has been recorded; that presumably through a ventriculovenous shunt (MacKeevor, 1966). However, bone, nodes and liver were involved in the others suggesting that environmental factors play some part in the determination of the sites of metastasis. It is interesting that other primary cerebral tumors more frequently metastasize to lung (Glasauer, 1963; Gyepes, 1966; Schenk, 1966).

The concept of lymphatic spread has not met with favor because brain and spinal cord do not possess lymphatics (Winkelman, 1952; Zimmerman, 1957) even though india ink injected into the occipital subarachnoid space in animals is reported to reach the cervical, posterior thoracic, posterior abdominal and pelvic nodes (Brierley, 1948).

Medulloblastomas frequently seed tumor cells along the spinal subarachnoid space, and their entry into lymphatics may be facilitated there through an extension of the subarachnoid space beyond the bony canal.

Surgery and radiotherapy have been incriminated as predisposing to extraneural spread. Surgery has preceded the diagnoses in all reported cases (Oberman, 1963). Radiation is thought to make tumor cells more anaplastic, and hence more likely to metastasize. However, we found no further dedifferentiation of cellular morphology following radiation.

\section{ACKNOWLEDGEMENT}

We gratefully acknowledge the help of the Department of Pathology at the Health Sciences Centre, Children's division, particularly that of Professor Jan Hoogstraten in reviewing these cases and the microscopic sections.

\section{BIBLIOGRAPHY}

BLACK, S. P. W., KEATS, T. E. (1964). Generalized osteosclerosis secondary to metastatic medulloblastoma of the cerebellum. Radiology 82: 395-400.

BRIERLEY, J. B., FIELD, E. (1948). Connection of spinal subarachoid space with the lymphatic system. Journal of Anatomy 82: 153-166.

CORRIN, B., MEADOWS, J. C. (1967). Skeletal metastasis from cerebellar medulloblastomas. British Medical Journal 2: 485-486.

DRACHMAN, D. A., WINTER, T. S., KARON, M. (1963). Medulloblastoma with extracranial metastasis. Archives of Neurology (Chicago) 9: 518-530.

GLASAUER, F. E., YUAN, R. H. P. (1963). Intracranial tumor with extracranial metastasis: Case report and review of literature. Journal of Neurosurgery 20: 474-493.

GYEPES, M. T., D'ANGIO, G. T. (1966). Extracranial metastasis from central nervous system tumors in children and adolescents. Radiology 87: 55-63.

LASSMAN, L. P., PEARCE, G. W., BANNA, M. et al (1969). Vincristine sulphate in the treatment of skeletal metastasis from cerebellar medulloblatoma. Journal of Neurosurgery 30: 42-49.

MacKEEVOR, L. C. and KING, J. D. (1966). Medulloblastoma with extracranial metastasis through a ventriculovenous shunt. American Journal of Clinical Pathology 46: 245-249.

MIKAYE, S., TOYAMA, M., ETANI, B., et al (1964). Medulloblastoma with extracranial spread. Journal of Neurosurgery $21: 416-418$.

NELSON, A. A. (1936). Metastasis of intracranial tumors. American Journal of Cancer 28: 1-12.

OBERMAN, H. A., HEWITT, W. C., KALIVODA, A. J. (1963). Medulloblastomas with distant metastasis. American Journal of Clinical Pathology 39: 148-160.

PATERSON, E. (1961). Distant metastasis from medulloblastoma of cerebellum. Brain 84: 301-309.

RUSSELL, D. S., RUBENSTEIN, L. J. (1959). Pathology of Tumors of the Nervous System. 208-210. The Williams \& Wilkins Company, Baltimore.

RUBENSTEIN, L. J., NORTHFIELD, D. W. C. (1964). Medulloblastoma and "cerebellar sarcoma." Brain 87: 379-412.

SCHENK, E. A. (1966). Medulloblastoma: Relationship to meningeal sarcoma. Archives of Pathology 82: pp. 363.

WEISS, L. (1955). A metastasizing ependymoma of the cauda equina. Cancer 8: 161-171.

WINKELMAN, N. W., JR., CASSELL, C., SCHLESINGER, B. (1952). Intracranial tumors with extracranial metastasis. Journal of Neuropathology and Experimental Neurology 11: 149-169.

ZIMMERMAN, H. M. (1957). The natural history of intracranial neoplasms with special reference to the gliomas. American Journal of Surgery 93: 913-924. 